\title{
Waning Of Real Power Loss By Modified Particle Swarm Optimization
}

\author{
Lenin $\mathbf{K}^{1 *}$, Ravindhranath Reddy $\mathbf{B}^{2}$, Surya Kalavathi $\mathbf{M}^{3}$ \\ ${ }^{1}$ Researcher, Jawaharlal Nehru Technological University, Kukatpally. \\ ${ }^{2}$ Deputy Executive Engineer, Jawaharlal Nehru Technological University, Kukatpally. \\ ${ }^{3}$ Professor of Electrical and Electronics Engineering, Jawaharlal Nehru Technological University, Kukatpally.
}

Received: December 03, 2016; Accepted: December 20, 2016; Published: January 11, 2017

*Corresponding author: Lenin K, Researcher, Jawaharlal Nehru Technological University, Kukatpally, Hyderabad, 500 085, India, Tel: 91 9677350862; E-mail: gklenin@gmail.com

\begin{abstract}
This paper presents Modified Particle Swarm Optimization (MPSO) algorithm for solving reactive power problem. A nonlinear decreasing weight factor used to change the fundamental ways of Particle Swarm Optimization (PSO). To allow full play to the approximation capability of the function of Back Propagation neural network \& overcome the main shortcomings of its liability to fall into local extreme value this study proposed a concept of modified PSO algorithm. Back Propagation network jointly to optimize the original weight, threshold value of network and incorporating the PSO algorithm into Back Propagation network to establish a Modified PSOBP network system. Proposed method MPSO progresses convergence speed and the capability to search optimal value. In order to evaluate the proposed MPSO algorithm, it has been tested on IEEE 30 bus system and compared to other reported standard algorithms and simulation results show that (MPSO) is more efficient than other algorithms in reducing the real power loss \& voltage profiles are within the limits.
\end{abstract}

Keywords: Modified Particle Swarm Optimization; Back Propagation; optimal reactive power; Transmission loss;

\section{Introduction}

Reactive power problem is one of the difficult optimization problems in power systems. Various mathematical techniques have been adopted to solve this optimal reactive power dispatch problem. These include the gradient method [1, 2], Newton method [3] and linear programming [4-7].The gradient and Newton methods suffer from the difficulty in handling inequality constraints. To apply linear programming, the input- output function is to be expressed as a set of linear functions which may lead to loss of accuracy. Recently global optimization techniques such as genetic algorithms have been proposed to solve the reactive power flow problem $[8,9]$. In recent years, the problem of voltage stability and voltage collapse has become a major concern in power system planning and operation. To enhance the voltage stability, voltage magnitudes alone will not be a reliable indicator of how far an operating point is from the collapse point [10]. The reactive power support and voltage problems are intrinsically related. Hence, this paper formulates the reactive power dispatch as a multi-objective optimization problem with loss minimization and maximization of Static Voltage Stability Margin (SVSM) as the objectives. The Particle Swarm Optimization (PSO) [11-15] was based on the optimal algorithm of swarm intelligence and it guides optimal search through swarm intelligence producing by the corporation and competition among particles. The artificial Neural Network possesses the ability of processing database in parallel, organizing and learning by itself. It has made great achievements in many fields. Especially neural network technique has been used in reliability and few researchers apply the method [16-20] to predict failures. Theoretically, Network [2132] may approach any continual nonlinear function. However, affected greatly by the sample, it may fall into local minimum value, thus it can't ensure that it converge the minimum value in overall situations. In our paper PSO algorithm is introduced into BP network optimization by using iterate algorithm of particle swarm instead of gradient correction algorithm of BP network. This method can shorten the time of training network and improve the convergence speed of BP algorithm. However, according to different system object, if basic particle swarm algorithm is modified, the performance of BP network is improved and its practicality is better. For balancing between the global search and the local search and improving the precision of the result, this study proposed the nonlinear strategies for decreasing inertia weight based on the idea of the existing linear decreasing inertia weight. The result of simulation shows that the optimizing methods speed the rapidity of convergence obviously and the precision of simulation increase greatly. The performance of Modified Particle Swarm Optimization (MPSO) has been evaluated in standard IEEE 30 bus test system and the simulation results show the best performance of the proposed algorithm.

\section{Objective Function}

\section{Active power loss}

The objective of the reactive power dispatch problem is to 
minimize the active power loss and can be written in equations as follows:

$$
\mathrm{F}=\mathrm{P}_{\mathrm{L}}=\sum_{\mathrm{k} \in \mathrm{Nbr}} \mathrm{g}_{\mathrm{k}}\left(\mathrm{V}_{\mathrm{i}}^{2}+\mathrm{V}_{\mathrm{j}}^{2}-2 \mathrm{~V}_{\mathrm{i}} \mathrm{V}_{\mathrm{j}} \cos \theta_{\mathrm{ij}}\right)
$$

Where F- objective function, $\mathrm{P}_{\mathrm{L}}$ - power loss, $\mathrm{g}_{\mathrm{k}}$ - conductance of branch, $\mathrm{V}_{\mathrm{i}}$ and $\mathrm{V}_{\mathrm{i}}$ are voltages at buses $\mathrm{i}, \mathrm{j}$, Nbr- total number of transmission lines in power systems.

\section{Voltage profile improvement}

To minimize the voltage deviation in PQ buses, the objective function (F) can be written as:

$$
F=P_{L}+\omega_{v} \times V D
$$

Where VD - voltage deviation, $\omega_{v}$ - is a weighting factor of voltage deviation.

And the Voltage deviation given by:

$$
V D=\sum_{i=1}^{N p q}\left|V_{i}-1\right|
$$

Where Npq- number of load buses

\section{Equality Constraint}

The equality constraint of the problem is indicated by the power balance equation as follows:

$$
P_{G}=P_{D}+P_{L}
$$

Where $\mathrm{P}_{\mathrm{G}}$ - total power generation, $\mathrm{P}_{\mathrm{D}}$ - total power demand.

\section{Inequality Constraints}

The inequality constraint implies the limits on components in the power system in addition to the limits created to make sure system security. Upper and lower bounds on the active power of slack bus $\left(\mathrm{P}_{\mathrm{g}}\right)$, and reactive power of generators $\left(\mathrm{Q}_{\mathrm{g}}\right)$ are written as follows:

$$
\begin{aligned}
& P_{\text {gslack }}^{\min } \leq P_{\text {gslack }} \leq P_{\text {gslack }}^{\max } \\
& Q_{g i}^{\min } \leq Q_{g i} \leq Q_{g i}^{\max }, i \in N_{g}
\end{aligned}
$$

Upper and lower bounds on the bus voltage magnitudes $\left(\mathrm{V}_{\mathrm{i}}\right)$ is given by:

$$
V_{i}^{\min } \leq V_{i} \leq V_{i}^{\max }, i \in N
$$

Uper and lower bounds on the transformers tap ratios $\left(\mathrm{T}_{\mathrm{i}}\right)$ is given by:

$$
T_{i}^{\min } \leq T_{i} \leq T_{i}^{\max }, i \in N_{T}
$$
by:

Upper and lower bounds on the compensators $\left(Q_{c}\right)$ is given

$$
Q_{c}^{\min } \leq Q_{c} \leq Q_{C}^{\max }, i \in N_{C}
$$

Where $\mathrm{N}$ is the total number of buses, $\mathrm{N}_{\mathrm{g}}$ is the total number of generators, $\mathrm{N}_{\mathrm{T}}$ is the total number of Transformers, $\mathrm{N}_{c}$ is the total number of shunt reactive compensators.

\section{Particle Swarm Optimization}

Particle Swarm Optimization Algorithm (PSO) is a population based optimization tool where the system is initialized with a population of random particles and the algorithm searches for optima by updating generations. Suppose in the D-dimensional objects searching space, there is a community composed of $\mathrm{N}$ particle. The "I" particle represent a D-dimensional vector, $X_{i}=\left(X_{i 1}, X_{i 2}, . . X_{i d}\right)$. It means that the "i" particle represents its position in this space. Every position of particle " $X$ " is a potential solution. If we put " $x$ " into objective function, we can know the adaptive value. We can know whether the " $x$ " is the optimal answer based on the adaptive value. The speed of particle is also a D-dimensional, it also recorded as $v_{i}=\left(v_{i 1}, v_{i 2}, . . v_{i d}\right)$. We record the particle I to the $\mathrm{h}$ times, the optimal position was $P_{i}=\left(P_{i 1}, P_{i 2}, . . P_{i d}\right)$. All the particles to the $\mathrm{h}$ times, the optimal position was $P_{g d}=\left(P_{i 1}, P_{i 2}, . . P_{i d}\right)$. The basic formulas are as follows:

$$
\begin{aligned}
& v_{i d}^{t+1}=w v_{i d}^{t}+c_{1} r_{1}^{t}\left(P_{i d}^{t}-x_{i d}^{t}\right)+c_{2} r_{2}^{t}\left(P_{g d}^{t}-x_{i d}^{t}\right) \\
& x_{i d}^{t+1}=x_{i d}^{t}+v_{i d}^{t+1}
\end{aligned}
$$

Where, $\boldsymbol{c}_{1} \& \boldsymbol{c}_{2}$ : Speeding coefficient, adjusting the maxim step length that flying the best particle in whole situation and the individual best particle respectively. Appropriate $c_{1}$ and $c_{2}$ speed up the convergence and avoid falling into partial optimality $r_{1} \& r_{2}$ : Random number between 0 and 1 , for controlling the weight of speed W: Inertia factor. It was oriented toward overall searching .We usually take the original value as 0.9 and make it to 0.1 with the addition and reduction of the times of iteration. It mainly used to total searching, making the searching space converge to a certain space. Then we can get the solution in high degree of accuracy by partial refined researching. With the increasing number of dimension of problems, basic PSO algorithm is easily falling into partial extreme value, thus influence the optimal function of algorithm. Someone brought up with improved algorithm. Many scholars' research shows [11-15] that " $w$ " has a great influence on the algorithm of particle swarm. When the " $w$ " is bigger, the algorithm has a strong ability in total searching and when the "W" is smaller, it is good for partial searching. Therefore, in recent years, some scholars brought up many schemes. LDW (Linearly Decreasing Inertia Weight) is given by,

$$
w=w_{\max }-\frac{t \times\left(w_{\max }-w_{\min }\right)}{t_{\max }}
$$

Where $w_{\max } \& w_{\min }$ : The maximum and minimum value of $\mathrm{W}, \mathrm{t}$ : The step of iteration, $t_{\max }$ : The maximum iteration step.

However, there are still problems in equation (12), so in the primary period of operation, if it detects the optimal point, 
it wants to converge to the optimal point promptly. However, the linear reduction slows down the speed of convergence of algorithm. In the later period of function, with the reduction of " $w$ ", it may make the ability of total searching decline and the variety awaken. Finally it may easily fall into partial optimum. In this text, we use the PSO method of nonlinear variation weight with momentum to improve this method is given by,

$$
w=w_{\max }-\frac{t \times\left(w_{\max }-w_{\min }\right)}{2^{\theta} t_{\max }}
$$

$2^{\theta}$ is momentum, when in $\theta=t / t_{\max }, \mathrm{t}$ is smaller, $2^{\theta}$ is near to 1 and $\mathrm{w}$ is near to $w_{\text {max }}$., it ensure the ability of total searching With the increasing of $t, w$ reduces in non linearity, ensuring the searching ability in partial areas. In the later $t=t_{\max }$ avoiding the problems caused by the decrease of $\mathrm{w}$. That is, the reduction ability of total searching and the decline of variety.

\section{Back Propagation (BP) Neural Network}

The standard Back Propagation (BP) Neural Network consists of input layer, one or several hidden layers and an input layer.

The node action function of BP neural network is generally " $\mathrm{S}$ " function. Common activation function $\mathrm{f}(\mathrm{x})$ is derivable sigmoid function:

$$
f(x)=\frac{1}{1+e^{-x}}
$$

Error function R is:

$$
R=\frac{\sum\left(Y_{m j}-Y_{j}\right)^{2}}{2}(j=1,2, . ., n)
$$

In this formula, $Y_{j}$ is expected out $Y_{m j}$ is actual output $\mathrm{n}$ is sample length.

The uniform expression of weight modified formula of BP algorithm is:

$$
w_{i j}^{(t+1)}=w_{i j}(t)+\eta \delta_{p j} o_{p j}
$$

The specific process of BP algorithm can be generalized as follows:

a. Select $\mathrm{n}$ samples as a training set.

b. Initialize weight and biases value in neural network. The initialized values are always random numbers between $(-1,1)$. Every sample in the training set needs the following processing:

c. According to the size of every connection weight, the data of input layer are weighted and input into the activation function of hidden layer and then new values are obtained. According to the size of every connection weight, the new values are weighted and input into the activation function of output layer and the output results of output layer are calculated.

d. If error exist between output result and desired result, the calculation training is wrong. e. Adjust weight and biases value.

f. According to new weight and biases values, the output layer is calculated. The calculation doesn't stop until the training set meets the stopping condition.

\section{Modified Particle Swarm Optimization (MPSO)}

We apply Particle Swarm Optimization (PSO) to train BP Network by optimizing the original weight and the threshold value. When the algorithm ends, we can find the point near the overall situation optimal point. In the particle swarm, every particle's position represents weights set among the BP network during the resent iteration. The dimension of every particle is decided by the number of the weight and the threshold value serving as connecting bridge.

The concrete process of MPSO is narrated as follows:

a. Initialization: $\boldsymbol{n}_{\boldsymbol{i}}$ is the number of neurons in the hidden layer no representing the number of neurons in input layer. So, the dimension of particle swarm $\mathrm{D}$ is:

$$
D=n_{i} \times n_{h}+n_{h} \times n_{\circ}+n_{h}++n_{\circ}
$$

b. Setting fitness function of particle swarm' in this text, we choose mean square error in BP Neural Network as fitness function of particle swarm:

$$
E=\frac{1}{M} \sum_{K}^{m} \sum_{j-1}^{n_{o}}\left(y_{k j}-\overline{y_{k j}}\right)
$$

$y_{k j}:$ The output in theory based on sample $\mathrm{K}$

$\overline{y_{k j}}$ : The virtual output based on sample K

M: The number of Neural Network

c. Using the improved particle swarm algorithm to optimize the weight and the threshold value of BP network.

Coming to the optimal weight and the threshold value based on equation given below,

$$
g_{\text {best }}=\left[\begin{array}{c}
h_{1}, h_{2}, . ., h_{n_{h}}, \mathrm{o}_{1}, \mathrm{o}_{2}, . ., \mathrm{o}_{\mathrm{n}_{\mathrm{o}}}, \mathrm{ih}_{1}, \mathrm{ih}_{2}, . ., \mathrm{ih}_{\mathrm{n}_{\mathrm{i}} \times \mathrm{n}_{\mathrm{h}}}, \\
\mathrm{ho}_{1}, \mathrm{ho}_{2}, . ., \mathrm{h}_{\mathrm{o}_{\mathrm{h}} \times \mathrm{n}_{\mathrm{o}}}
\end{array}\right]
$$

$\mathrm{h}_{\mathrm{i}}\left(=1,2, . ., \mathrm{n}_{\mathrm{k}}\right)$ : The threshold value in the hidden layer $\mathrm{o}_{\mathrm{i}}\left(\mathrm{i}=1,2, . ., \mathrm{n}_{\mathrm{o}}\right)$ : The threshold value in the output layer $\mathrm{ih}_{\mathrm{i}}\left(\mathrm{i} 1,2, . ., \mathrm{n}_{\mathrm{i}} \times\right)$ : The weight between the hidden layer and the input layer $\mathrm{ho}_{\mathrm{i}}\left(\mathrm{i}=1,2, . ., \mathrm{n}_{\mathrm{h}} \times \mathrm{n}_{\mathrm{o}}\right)$ : The weight between the hidden layer and the output layer

d. Let the optimal weight and the threshold value be as the original weight and then put them into Neural Network for training. Adjusting the weight and the threshold value based on BP algorithm until the function index of the network's Mean Square Error (MSE) <e. "e" is the preset 
expected index.

\section{Simulation Results}

Validity of proposed Modified particle swarm optimization (MPSO) algorithm has been verified by testing in IEEE 30-bus, 41 branch system and it has 6 generator-bus voltage magnitudes, 4 transformer-tap settings, and 2 bus shunt reactive compensators. Bus 1 is taken as slack bus and 2, 5, 8, 11 and 13 are considered as PV generator buses and others are PQ load buses. Control variables limits are given in Table 1 . In Table 2 the power limits of generators buses are listed.

Table 3 shows the proposed MPSO approach successfully kept the control variables within limits.Table 4 narrates about the performance of the proposed MPSO algorithm. Figure 1 show about the voltage deviations during the iterations and Table 5

\begin{tabular}{|l|l|l|l|}
\hline Table 1: Primary Variable Limits $(\mathrm{Pu})$ & \\
\hline Variables & Min. & Max. & Category \\
\hline Generator Bus & 0.90 & 1.11 & Continuous \\
\hline Load Bus & 0.91 & 1.01 & Continuous \\
\hline Transformer-Tap & 0.92 & 1.01 & Discrete \\
\hline Shunt Reactive Compensator & -0.10 & 0.30 & Discrete \\
\hline
\end{tabular}

Table 2: Generators Power Limits

\begin{tabular}{|l|l|l|l|l|}
\hline Bus & Pg & Pgmin & Pgmax & Qgmin \\
\hline 1 & 96.00 & 49 & 200 & -19 \\
\hline 2 & 79.00 & 18 & 79 & -19 \\
\hline 5 & 49.00 & 14 & 49 & -11 \\
\hline 8 & 21.00 & 11 & 31 & -14 \\
\hline 11 & 21.00 & 11 & 28 & -12 \\
\hline 13 & 21.00 & 11 & 39 & -14 \\
\hline
\end{tabular}

Table 3: After optimization values of control variables

\begin{tabular}{|c|c|}
\hline Control Variables & MPSO \\
\hline V1 & 1.0541 \\
\hline V2 & $1.0452 \mathrm{v}$ \\
\hline V5 & 1.0263 \\
\hline V8 & 1.0374 \\
\hline V11 & 1.0745 \\
\hline V13 & 1.0575 \\
\hline T4,12 & 0.00 \\
\hline T6,9 & 0.01 \\
\hline T6,10 & 0.90 \\
\hline T28,27 & 0.91 \\
\hline Q10v & 0.10 \\
\hline Q24 & 0.10 \\
\hline Real power loss & 4.2809 \\
\hline Voltage deviation & 0.9085 \\
\hline
\end{tabular}

\begin{tabular}{|l|l|}
\hline \multicolumn{2}{|l|}{ Table 4: Performance of MPSO algorithm } \\
\hline Iterations & 32 \\
\hline Time taken (secs) & 8.91 \\
\hline Real power loss & 4.2809 \\
\hline
\end{tabular}

Table 5: Comparison of results

\begin{tabular}{|l|l|}
\hline Techniques & Real power loss (MW) \\
\hline SGA(Wu et al., 1998) [33] & 4.98 \\
\hline PSO(Zhao et al., 2005) [34] & 4.9262 \\
\hline LP(Mahadevan et al., 2010) [35] & 5.988 \\
\hline EP(Mahadevan et al., 2010) [35] & 4.963 \\
\hline CGA(Mahadevan et al., 2010) [35] & 4.980 \\
\hline AGA(Mahadevan et al., 2010) [35] & 4.926 \\
\hline CLPSO(Mahadevan et al., 2010) [35] & 4.7208 \\
\hline HSA (Khazali et al., 2011) [36] & 4.7624 \\
\hline BB-BC (Sakthivel et al., 2013) [37] & 4.690 \\
\hline MCS(Tejaswini sharma et al.,2016) [38] & 4.87231 \\
\hline Proposed MPSO & 4.2809 \\
\hline
\end{tabular}

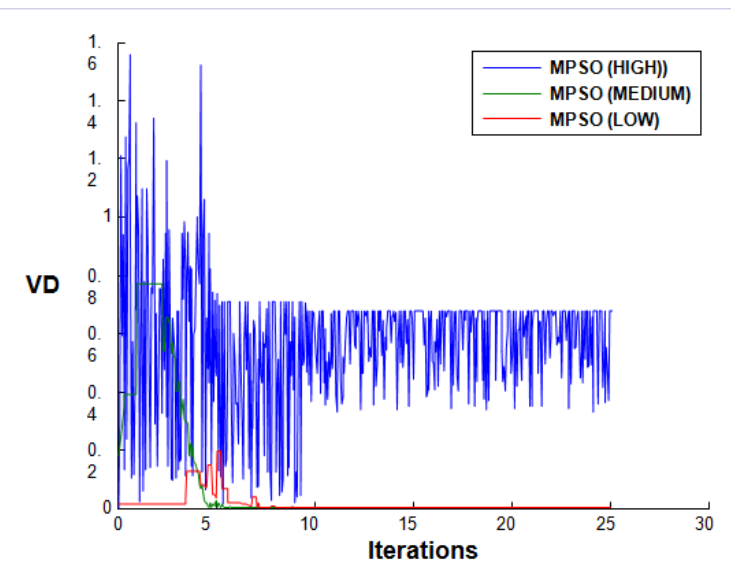

Figure 1: Voltage Deviation (VD) Characteristics

list out the overall comparison of the results of optimal solution obtained by various methods.

\section{Conclusion}

In this paper an inventive approach Modified Particle Swarm Optimization (MPSO) algorithm is used to solve reactive power problem, by considering various constraints. The efficiency of the projected Modified particle swarm optimization (MPSO) method is demonstrated by testing it on standard IEEE 30-bus system and the real power loss has been considerably reduced when compared to other reported standard algorithms \& voltage profile are well within the specified limits .

\section{References}

1. Alsac 0, Scott B. Optimal load flow with steady state security. IEEE Transaction. 1973:PAS 93(3):745-751. 
2. Lee KY, Paru YM, Oritz JL. A united approach to optimal real and reactive power dispatch. IEEE Transactions on power Apparatus and systems. 1985;PAS-104(5):1147-1153.

3. Monticelli A, Pereira MVF, Granville S. Security constrained optimal power flow with post contingency corrective rescheduling. IEEE Transactions on Power Systems. 1987;2(1):175-182.

4. Deeb N, Shahidehpur SM. Linear reactive power optimization in a large power network using the decomposition approach. IEEE Transactions on power system. 1990;5(2):428-435.

5. Hobson E. Network consrained reactive power control using linear programming. IEEE Transactions on power systems. 1980;PAS99(4):868-877.

6. Lee KY, Park YM, Oritz JL. Fuel -cost optimization for both real and reactive power dispatches. IEE Proc C. 1984;131(3):85-93.

7. Mangoli MK, Lee KY. Optimal real and reactive power control using linear programming. Electr Power Syst Res. 1993;26(1):1-10.

8. Berizzi A, Bovo C, Merlo M, Delfanti M. A GA approach to compare ORPF objective functions including secondary voltage regulation. Electric Power Systems Research. 2012;84(1):187-194.

9. Devaraj D, Yeganarayana B. Genetic algorithm based optimal power flow for security enhancement. IEE proc-Generation, Transmission and Distribution. 2005;152(6):899-905.

10. Canizares CA, de Souza ACZ, Quintana VH. Comparison of performance indices for detection of proximity to voltage collapse. 1996;11(3):1441-1450.

11. Eberhart RC, Kennedy J. A new optimizer using particle swarm theory Proceeding of the 6th International Symposium on Micro Machine and Human Science. 1995:39-43.

12.Eberhart RC, Shi Y. Particle swarm optimization: Development, applications and resources. Proceeding of Congress on Evolutionary Computation. 2001:81-86.

13. Hai-Dong Z, XU-Dong M, Shi-Pin L. Military plane fault prediction system based on neural network model. J Syst Eng Electron. 2003;25(7):894-896.

14. Hao P, Xiao-Lei H. BP network training algorithm based on particle swarm optimization. Comp Eng Appl. 2008;44(9):67-69.

15. Jiang-Hong $\mathrm{H}$, Zheng-Rong L, Zhen-Chun W. Adaptive particle swarm optimization algorithm and simulation. J Syst Simul. 2006;18(10):2969-2971.

16. Jie-Ping C, Dao-Cai C, Li L, ShuaiYing L, Miao Y. Application of BP network model based on PSO for the forecast of drought and flood. J Shengyang Agric Univ. 2009;40(1):118-121.

17. Jin-Yong M, Chang-Qing H, Hua G, Kejie L. Study on fault forecasting of air control equipment based on neural network. Syst Eng Electron. 2004;26(7):992-993.

18. Kennedy J, Eberhart R.C. Particle swarm optimization. Proceeding of IEEE International Conference on Neural Networks. 1995:1942-1948.

19. Michael JC, David EM, Thomas JS, Malhotra A. Comparison of electronics-reliability assessment approaches. IEEE Trans Reliabil. 1993;42(4):542-546.
20. Shan-Yu Y, Hong-De W. Analysis on main fan first failure time based on neural network technique. J China Coal Soc. 2005;30(6):741-745.

21.Xiang, L, Ji-Feng C, Jun X. Shu-xia Y, Shang-dong Y. Power demand forecasting based on BP neural network optimized by clonal selection particle swarm. J Hunan Univ. 2008;35(6):41-52.

22.Xiao-Rong W, Shu-Xian L. Study on BP neural network optimization based on improved PSO algorithm. J Bohai Univ. 2008;29(2):189-192.

23.Xiu-Ye W, Hong-Xia P. The Improvement of Particle Swarm and Intelligent Trouble Diagnosis. China Defense Press. 2010:101-102.

24.Xuan H, Jun Z, Zhi-Hui Z. Faster particle swarm optimization with random inertia weight. Comp Eng Design. 2009;30(3): 647-650.

25. Yi-Shan X, Bi Z, Xiu-Wen Y. BP neural network and its applications based on improved PSO. Comp Eng Appl. 2009;45(35): 233-235.

26. Ying-Jie L, Chang-Hua $\mathrm{H}$. The performance analysis of missile inertia device fault prediction based on neural networks. Tact Miss Technol. 2005;27(2):52-55.

27. Song H, Maité BP. A 2-D discrete-time model of physical impairments in wavelength-division multiplexing systems. Journal of Lightwave Technology. 2012;30(5):713-726.

28. Song H, Maité BP. Range of influence and impact of physical impairments in long-haul DWDM systems. J Lightwave Technology. 2013;31(6):846-854.

29. Song H, Maite BP. Model-centric nonlinear equalizer for coherent longhaul fiber-optic communication systems. Global Communications Conference (GLOBECOM). 2013.

30. Wei W, Yong Q. Information potential fields navigation in wireless AdHoc sensor networks. Sensors. 2011;11(5):4794-4807.

31. Wei W, Xu Q, Wang L, Hei XH, Shen P, Shi W, et al. GI/Geom/1 queue based on communication model for mesh networks. International Journal of Communication Systems. 2014;27(11):3013-3029.

32. Wei W, Yang XL, Shen PY, Zhou B. Holes detection in anisotropic sensornets: Topological methods. International Journal of Distributed Sensor Networks. 2012.

33. Wu QH, Cao YJ, Wen JY. Optimal reactive power dispatch using an adaptive genetic algorithm. Int J Elect Power Energy Syst. 1998;20(8):563-569.

34.Zhao B, Guo CX, CAO YJ. Multiagent-based particle swarm optimization approach for optimal reactive power dispatch. IEEE Trans Power Syst. 2005;20(2):1070-1078.

35. Mahadevan. K, Kannan PS. Comprehensive Learning Particle Swarm Optimization for Reactive Power Dispatch. Applied Soft Computing. 2010;10(2):641-652.

36. Khazali AH, Kalantar M. Optimal Reactive Power Dispatch based on Harmony Search Algorithm. International Journal of Electrical Power \& Energy Systems. 2011;33(3):684-692.

37. Sakthivel S, Gayathri M, Manimozhi V. A Nature Inspired Optimization Algorithm for Reactive Power Control in a Power System. International Journal of Recent Technology and Engineering. 2013;2(1):29-33.

38. Tejaswini Sharma, Laxmi Srivastava, Shishir Dixit. Modified Cuckoo Search Algorithm For Optimal Reactive Power Dispatch. Proceedings of 38 th IRF International Conference. 2016:4-8. 